\title{
Properties of porous heat-resistant composition materials. Part II
}

\author{
P.G. Kudryavtsev iD \\ Polymate Ltd - Israel Nanotechnology Research Center, Migdal HaEmek, Israel \\ Corresponding author: e-mail: pgkudr89@gmail.com \\ (c) Kudryavtsev P.G., 2020
}

\begin{abstract}
This article is a continuation of a series of articles on the production of porous composite nanomaterials. This paper presents an overview of the properties of porous, heat-resistant inorganic composite materials. The physicochemical and mechanical characteristics of various porous refractory materials produced industrially are presented. A separate class of materials with a regular and quasi-regular porous structure is considered. Such materials include the so-called cellular or «lattice» materials, that are becoming widely applied in modern industry. An example of such materials is ceramic foam - a sintered ceramic material with a foamy cellular structure. A special group of materials with opal pore structure has been also focused. Synthetic opals have received intensive development in recent years because they are model objects for the development and research of new spatial-periodic structures with nonlinear optical properties. Such structures include composites based on classical and inverted opals, in which the pores are filled with various dielectric, semiconductor, or metallic substances. The optical properties of these systems are determined by the size of the close-packed particles, as well as the dielectric constant of the components.
\end{abstract}

KEYWORDS: porous materials, heat-resistant materials, cellular materials, opal structures.

FOR CITATION: Kudryavtsev P.G. Properties of porous heat-resistant composition materials. Part II. Nanotehnologii v stroitel'stve = Nanotechnologies in Construction. 2020, Vol. 12, no. 1, pp. 15-20. DOI: 10.15828/2075-8545-2020-12-1-15-20.

\section{Materials with opal pore structure}

Another representative of materials with a regular porous structure are opals. Opal - one of the most famous jewelry stones. Its name comes from the Latin «opalus»- a precious stone. Opals are characterized by a variety of color games, in connection with which, a number of varieties of noble opal stand out. Opal is a hydrogel of silicon dioxide $\mathrm{SiO}_{2} \cdot \mathrm{xH}_{2} \mathrm{O}$ with variable water content. Sometimes in opals, there are impurities of organic matter. Opals can be colorless or painted in white, yellow, green, red, brown and black. Opals are characterized by gloss, as well as opalescence. The hardness of opal is $5.5 \div 6$ on the Mohs scale, but it is very fragile. The refractive index is $1.44 \div 1.46$. The density is $1.8 \div 2.3 \mathrm{~g} / \mathrm{cm}^{3}[52]$.

The development of electron microscopy methods made it possible to establish that noble opals consist of uniformly sized $\mathrm{SiO}_{2}$ spherical particles with a diameter of 150-250 nm, which in turn are formed from smaller globular structures with a diameter of 5-50 nm (Fig. 13 and 14).

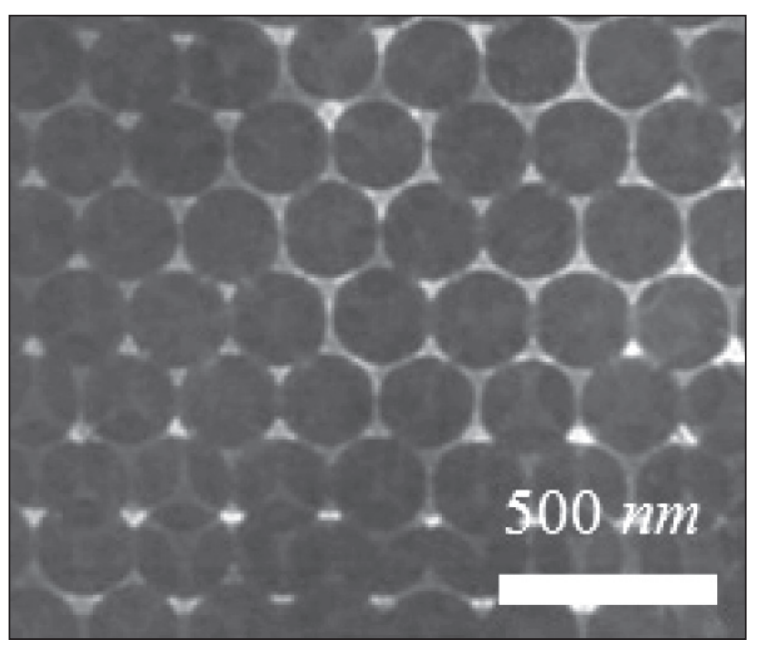

Fig. 13. Electron microscopic image of opal obtained in the transmission mode

The voids of the packing of $\mathrm{SiO}_{2}$ spheres are filled with amorphous silicon oxide. The intensity of diffracted light is determined by the «ideal» packaging of microspheres 

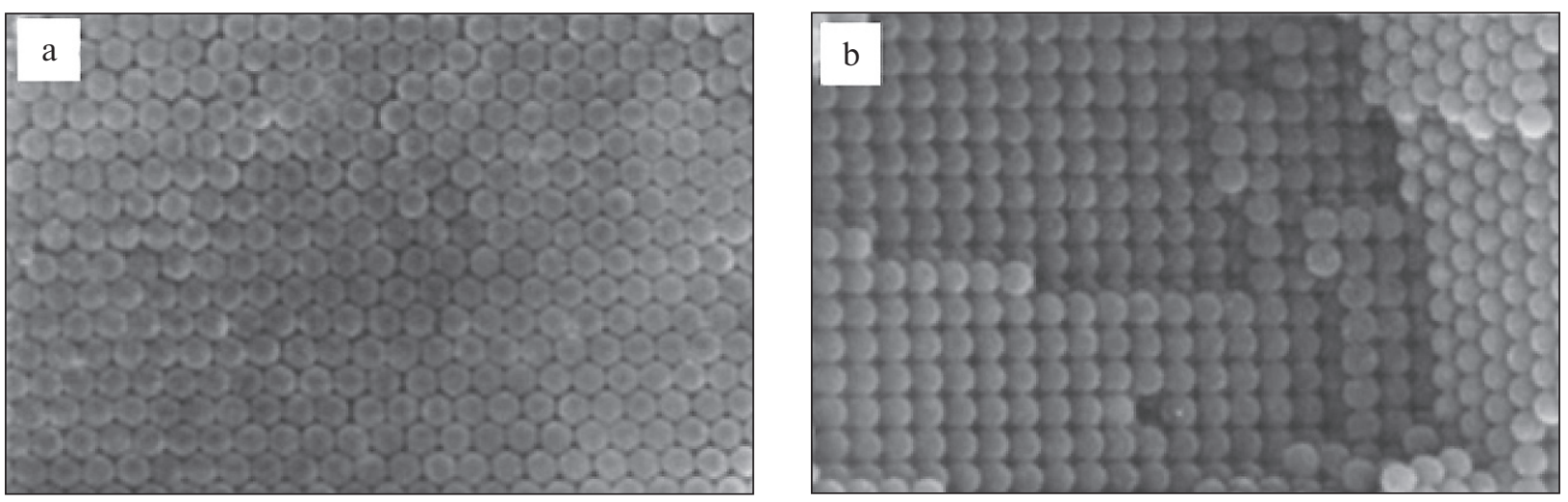

Fig. 14. Photomicrographs of synthetic opal obtained by scanning electron microscopy [52]:

$\mathrm{a}-$ Facets (111); b - (100)

and the difference in the refractive indices of crystalline and amorphous silicon oxide. The most noticeable iris is observed for black opals, the difference in refractive indices for which is 0.02 . The formation of opal in nature is associated with hydrothermal processes or weathering. Noble opals are extremely rare. Even in the very rich deposits of Australia, noble varieties of opal make up no more than $1 \%$.

Synthetic opals are model objects for the development and investigation of new spatially periodic structures possessing nonlinear optical properties. Such structures include composites based on opals, in which the pores are filled with various dielectric, semiconductor or metal compounds, as well as inverted opals. The optical properties of these systems are determined by the size of the close-packed particles, as well as by the dielectric permittivity of the components.

Synthetic opals are model objects for the development and investigation of new spatially periodic structures possessing nonlinear optical properties. Such structures include composites based on opals, in which the pores are filled with various dielectric, semiconductor or metal compounds, as well as inverted opals. The optical properties of these systems are determined by the size of the close-packed particles, as well as by the dielectric permittivity's of the components.

The study of such materials intensified more than ten years ago, when it was theoretically predicted that photonic crystals active in the visible and near infrared range would have a variety of exciting optical properties [42-44]. Therefore, the term «crystal» assumes that these patterns should consist of perfect ordered arrays of solids. However, unlike ordinary crystals, which are of the order of several angstroms in length, the photonic crystals should be of the order of length in the submicron scale.

These systems, called colloidal crystals, consist of either silica or polymer colloids; like a natural gemstone opal, which they resemble, they refract visible and near infrared light, as a result of submicron diameters of colloids. In colloidal crystals of silicon dioxide, there is no total photonic band gap. Stronger photon behavior can be realized if the dielectric contrast of these systems is increased when colloidal crystals are used as templates for structuring solids with higher refractive indices. The resulting macroporous samples, commonly referred to as reverse opals, have arrays of air voids within built-in solids with a high refractive index, such as ceramics or metals. In these inverted structures, a complete photonic band gap can be achieved if the contrast of refractive indices between spheres and interstitial regions exceeds 2.8 [45-47].

To create photonic crystals, synthetic opals are most often used as the initial matrices. Their structure has a three-dimensional sublattice of interconnected nanosized pores formed between close-packed spheres of silicon dioxide. The pore sizes vary within hundreds of nanometers; the dimensions of the pore-binding channels reach tens of nanometers. Opals are characterized by open porosity and, consequently, the pore sublattice in them is available for filling with other substances. The main requirement for the formation of nanocomposites based on photonic crystals is the completeness of the filling of the porous structure, which imposes significant limitations on the choice of the synthesis method. To fill the porous structure, melt methods (impregnation by melts or a method of introduction from a solution in a melt), impregnation with strongly concentrated solutions, followed by evaporation of the solvent, filling the photonic crystal with a colloid solution of nanoparticles, introducing compounds in hydrothermal and supercritical conditions, etc. are usually used.

The formation of macroporous polymers from colloidal films provides the simplest illustration of the general methodology used to convert opals to inverted opals $[48,49]$. The process begins with a close-packed colloidal crystal, or normal opal, in which $24 \%$ of the volume oc- 

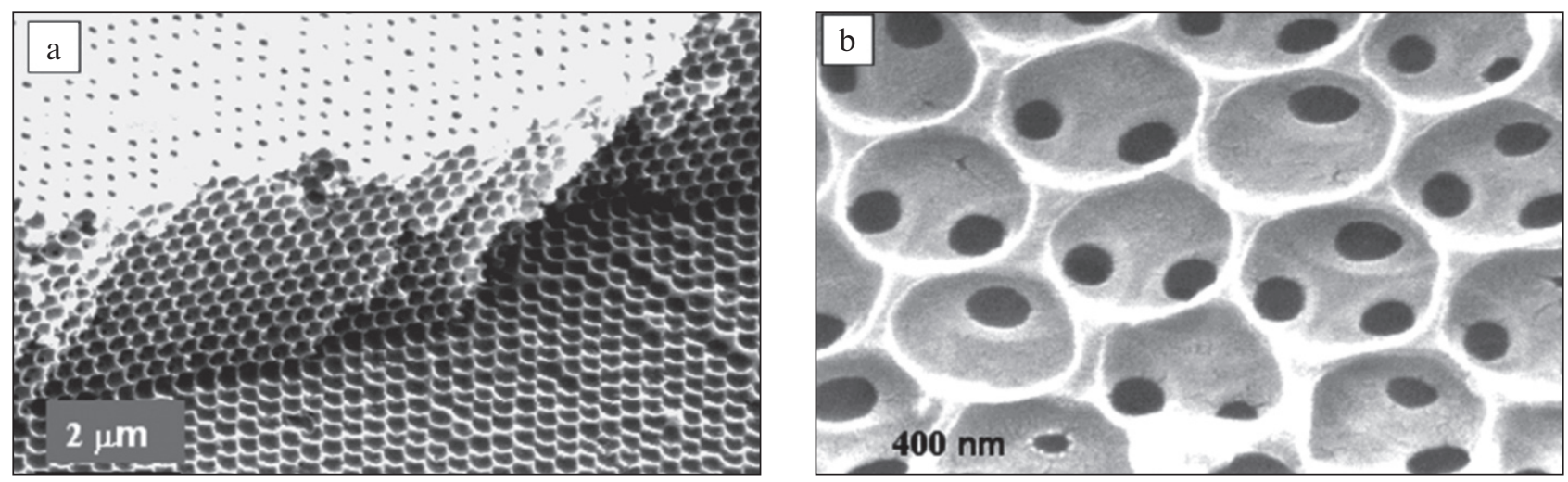

Fig. 15. SEM photomicrograph of reverse opal made of polystyrene [48]:

a - after removing the silica template by chemical etching, the sample contains a large proportion of the free volume; $\mathrm{b}-$ an enlarged view of the porous structure

cupies air. Liquid monomer is introduced into the pores of opal, usually through a capillary interaction. A suitable monomer is then photochemical or thermally polymerized around the particles. To remove the colloids, then chemical etching is used, in the case of silica, or thermal decomposition, in the case of polystyrene. With results, they are an exact replica of opal, which now consists of $76 \%$ air in the form of spherical voids in the original locations of the colloids (Fig. 15a).

Spherical voids are in the same place as the initial colloidal silica. An important feature of inverted opals is the creation of small «windows» observed between large voids (Fig. 15b); they are the result of neck formation between the original colloids. An enlarged view of the porous structure shows small holes that connect spherical voids. These forms are formed around the necks that exist between the silica colloids and provide an interconnected network of channels for the chemical etching process. Their diameter is uniform (variance of values of $\sigma \sim 6 \%$ ), and their average size can be varied by adjusting the viscosity of the monomer solution. Without this network of small voids, the chemical etching procedure used to remove the silicon dioxide would not have been able to open the entire volume of the sample. These necks can have a significant effect on optical properties, in that they represent a small departure from the idealized face centered lattice of balloons that barely touch their neighbors [47].

Thus, a wide variety of macroporous polymers was manufactured; with the exception of conductive polymers [50], the contrast of their refractive indices is similar to their original systems of silicon dioxide and air. To form stronger photonic crystals, inverted opals should be obtained from materials with higher refractive indices.

As the introduced substances, it is promising to use semiconductor or dielectric materials with high refractive indices such as $\mathrm{GaP}, \mathrm{SnO}, \mathrm{ZrO}_{2}, \mathrm{WO}_{3}$, etc. Moreover, controlling the degree of filling of the pores with the substance allows changing the average permittivity of the composite and thus «rearranging» the position of the photonic band gap opal. A further increase in the dielectric contrast can be achieved by selective etching of $\mathrm{SiO}_{2}$ from
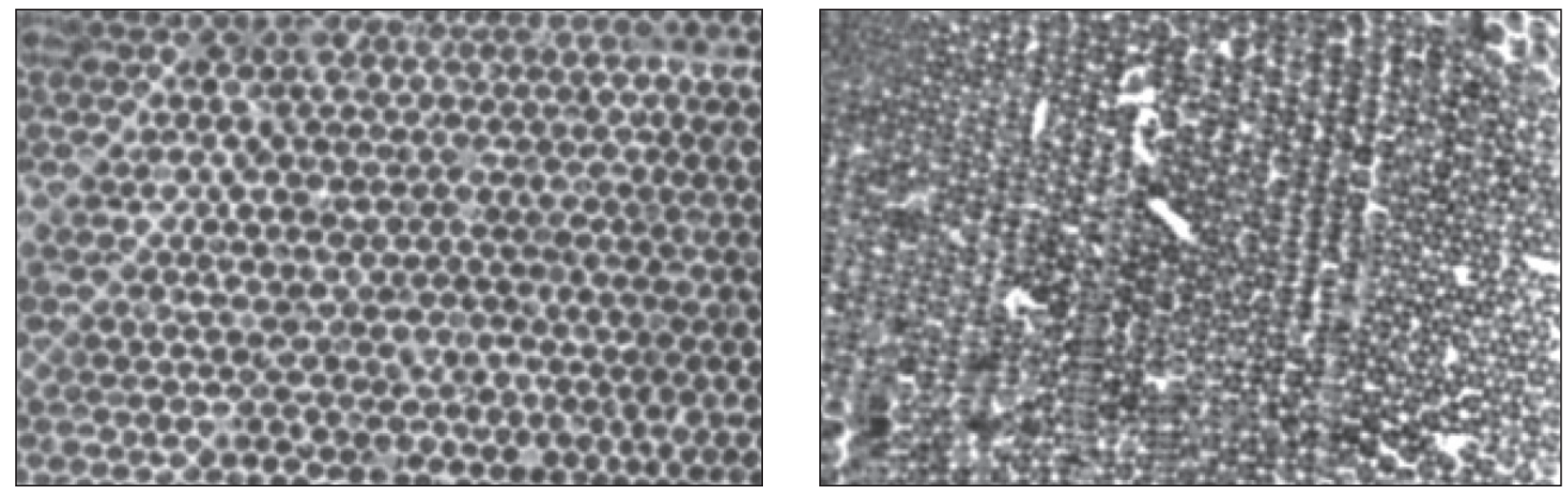

Fig. 16. A photomicrograph of inverted opals based on $\mathrm{SiO}_{2}$ and $\mathrm{WO}_{3}[46,47]$ 
the composite. The spatially ordered nanostructures thus obtained are called inverted or inverted opals (Fig. 16).

In these inverted structures, the total photonic band gap between, can be achieved if the contrast of refractive indices between spheres and interstitial regions exceeds 2.8 [46, 47]. For interstitial materials, such as silicon (with a refractive index of $\sim 3.4$ ), this discontinuity occurs at a wavelength of $\sim 3.5$ times the radius of the spheres forming this structure $[46,51]$.

\section{CONCLUSION}

In this paper, a review of the properties of porous heat-resistant inorganic composite nanomaterials was presented. The physicochemical and mechanical characteristics of various porous refractory materials manufactured industrially were considered. The greatest successes in the production of lightweight refractory materials were achieved in the USA as a result of the development of production and flight tests of the space shuttle reusable spacecraft thermal protection system. A class of materials with a regular and quasiregular porous structure is separately considered as an example. Such materials include the so-called cellular, cellular or «lattice» materials, which are increasingly used in modern technology. An example of such materials is foam ceramics - a sintered ceramic material with a foam cellular structure. For materials with a lattice structure, a model was proposed that relates their density and strength to their structure. So with a low connectivity racks, they have low stiffness, because the configuration of their cells allows them to bend. This assumption leads to the idea of lattice structures built from micro trusses. This assumption made it possible to apply the generalized Maxwell rule and Maxwell criterion to these materials. They provide an analytical approach for the design of lattices with a predominance of tensile forces in their structure and, accordingly, to obtain stronger and lighter materials. A special group of materials with an opal pore structure is considered separately. Synthetic opals have been intensively developed in recent years because they are model objects for the development and study of new spatially periodic structures with nonlinear optical properties. Such structures include composites based on classical and inverted opals, in which the pores are filled with various dielectric, semiconductor, or metallic substances. The optical properties of these systems are determined by the size of the close-packed particles, as well as by the dielectric constants of the components.

Part I of the paper «Properties of porous heat-resistant composition materials» by Kudryavtsev P.G. has been published in the issue 6/2019 of the journal «Nanotechnologies in Construction».

\section{REFERENCES}

1. Kudryavtsev P.G. Composition and structure of porous heat-resistant inorganic composite materials. Nanotehnologii v stroitel'stve $=$ Nanotechnologies in Construction. 2018, Vol. 10, no. 4, pp. 75-100. DOI: dx.doi.org/10.15828/2075-8545-201810-4-75-100. (In Russian).

2. Kudryavtsev P.G. Structure of pores in solid porous bodies. Part I. Nanotehnologii v stroitel'stve $=$ Nanotechnologies in Construction. 2018, Vol. 10, no. 5, pp. 80-103. DOI: dx.doi.org/10.15828/2075-8545-2018-10-5-80-103. (In Russian).

3. Kudryavtsev P.G. Structure of pores in solid porous bodies. Part II. Nanotehnologii v stroitel'stve $=$ Nanotechnologies in Construction. 2018, Vol. 10, no. 6. (In Russian).

4. Krasulin Yu.P., Timofeev V.N., Barinov S.M., Ivanov A.B., Asonov A.I., Shnyrev G.A. Porous structural ceramics, M.: Metallurgy, 1980, 100 s. (In Russian).

5. Galakhov F.Ya., Areshev MP, Vavilonova V.T., Averyanov V.I. Determination of the boundaries of the metastable segregation in the silica part of the $\mathrm{TiO}_{2}-\mathrm{SiO}_{2}$ system. Izvestiya AN SSSR. Inorganic materials. 1974. Vol. 10, No. 1, C. 179-180. (In Russian).

6. Hammel E.C., Ighodaro O.L.-R., Okoli O.I., Processing and properties of advanced porous ceramics: An applicationbased review, Ceramics International, Vol. 40, 10, Part A, 2014, P. 15351-15370, ISSN 0272-8842, https://doi.org/10.1016/j. ceramint.2014.06.095.

7. Kudryavtsev PG, Kavalerova OB, Pilipenko V.G., Kazakova I.L., Vorobev O.A., Kropacheva M.V. The method of obtaining refractory heat-resistant material, Patent of the USSR № 1787890, According to the application number 4900496/33 from 01.01.91, publ. BI No. 2 of 01/15/93. (In Russian).

8. Konti K., Tsuneharu S. Porous ceramics for kerosene burners. Japan patent 57-23669, 13.01.73, C 34 B.

9. Efimov G.V., Shlemov B.A. and others. The mass for the manufacture of lightweight refractory material. Patent of the USSR № 923997, C 04 B 21/02. (In Russian).

10. Semnina N.V., Evdokimova Z.U., Zamyatin S.R. Raw mix for the manufacture of lightweight refractory products. Patent of the USSR № 580199, C 048 35/00, 15.06.76. (In Russian). 
11. Khiromitsu T., Sanzakira M., Shigeru K., Makoto O., Tadashi S. Method of making porous ceramics. Japan patent 57-49508, C 04 B 21/06, 12.01.78.

12. Konti K., Khiromitsu T., Tsuneharu S. Porous ceramics for the manufacture of parts for liquid heaters. Japan patent 57-23668, 12.01.78, C 84 B 21/06.

13. Tisato M., Macao I. Retrieval of products from porous ceramics. Japan patent 53-60653, 05.10.81, C 04 B 21/06.

14. Kalinchev V.A., Kunikov B.T., Melnikov E.V., Peynova E.V., Avsineeva N.K. Technological features of the formation of heat-resistant compositions of microspheres. Proceedings MVTU Bauman, vol. 20, The use of plastics in industry. M., 1984, p. 26-31. (In Russian).

15. Rashidi S., Esfahani J.A., Karimi N. Porous materials in building energy technologies - A review of the applications, modelling and experiments, Renewable and Sustainable Energy Reviews, Vol. 91, 2018, P. 229-247, ISSN 1364-0321, https://doi. org/10.1016/j.rser.2018.03. 092.

16. Sorin M.N., Kunalova T.P., Taodu A.N., Krivoruchko P.P., Pitak N.V. The method of preparation of refractory insulating fibrous material, Patent of the USSR № 1033487, 31.03.82. (In Russian).

17. Collection of technological instructions. Sukhoi Log, 1985. (In Russian).

18. Schramm N. HRSI and LRSI - the early years. Ceramic Bull., 1981, V. 60, No 1, p. 1194-1195.

19. Leiser D.B., Smith M., Goldstein H.E. Developments in Fibrous Refractory Composite Insulation. Am. Ceram. Soc. Bull. 1981. V. 60. No 11. P. 1201-1204.

20. Study of the strength and regularity of changes in the mechanical properties of new composite and refractory materials in a wide range of temperatures and loading rates, taking into account the structural, technological and other factors associated with the operation of real products. No. of state. registration 77007301, Kiev, 1982, Vol. 3, 89 p. (In Russian).

21. Kheifets L.I., Neymark A.V. Multiphase processes in porous media. M: Chemistry, 1982. (In Russian).

22. Buckley I.D., Stronhal G., Ganaler I.I. Am. Ceram. Soc. Bull., 1981, V. 60, № 11, p. 1196-1199.

23. Gent, A.N., Thomas, A.G. (1959). The deformation of foamed elastic materials. J. Appl. Polym. Sci., Vol. 1, № 1, pp. 107113. doi: 10.1002/app.1959.070010117.

24. Ashby M.F., Medalist R.F.M. The mechanical properties of cellular solids, Metallurgical Transactions A, 1983, Vol. 14, № 9, pp. 1755-1769.

25. Brezny, R. Green, D.J. Fracture Behavior of Open-Cell Ceramics. Journal of the American Ceramic Society, 1989, Vol. 72, pp. 1145-1152. doi: 10.1111/j.1151-2916.1989.tb09698.x.

26. Brezny, R., Green, D.J. The effect of cell size on the mechanical behavior of cellular materials, Acta Metallurgica et Materialia, Vol. 38, 12, 1990, pp. 2517-2526, doi:10.1016/0956-7151(90)90263-G.

27. Brezny, R. and Green, D.J. Factors Controlling the Fracture Resistance of Brittle Cellular Materials. Journal of the American Ceramic Society, 1991, Vol. 74, p.1061-1065. doi: 10.1111/j.1151-2916.1991.tb04343.x.

28. Nanjangud, S.C., Brezny, R. and Green, D. J. (1995), Strength and Young's Modulus Behavior of a Partially Sintered Porous Alumina. Journal of the American Ceramic Society, 78: 266-268. doi: 10.1111/j.1151-2916.1995.tb08401.x.

29. Huang, J.S., Gibson, L.J. Fracture toughness of brittle honeycombs, Acta Metallurgica et Materialia, Vol. 39, 7, 1991, P. 1617-1626, doi:10.1016/0956-7151(91)90249-Z.

30. Huang, J.S., Gibson, L.J. Fracture toughness of brittle foams, Acta Metallurgica et Materialia, Vol. 39, 7, 1991, P. 1627-1636, doi:10.1016/0956-7151(91)90250-5.

31. Huang, J.S., Gibson, L.J. Optimum cell size and density of brittle foams, Journal of Materials Science Letters, 1993, Vol. 12, 8, pp. 602-604, DOI: 10.1007/BF00278338.

32. Triantafillou, T.C., Gibson, L.J. Multiaxial failure criteria for brittle foams, International Journal of Mechanical Sciences, Vol. 32, 6, 1990, P. 479-496, doi:10.1016/0020-7403(90)90154-B.

33. Vedula, V.R., Green, D.J., Hellman, J.R. Thermal fatigue resistance of open cell ceramic foams, Journal of the European Ceramic Society, Vol. 18, 14, 1998, P. 2073-2080, doi:10.1016/S0955-2219(98)00159-9.

34. Vedula, V.R., Green, D.J., Hellman, J.R., Segall, A.E. Test methodology for the thermal shock characterization of ceramics, Journal of Materials Science 1998, Vol. 33, 22, pp. 5427-5432, DOI: 10.1023/A:1004410719754.

35. Scheffler M., Colombo P. (Eds.) Cellular Ceramics: Structure, Manufacturing, Properties and Applications. 2005, WILEYVCH Verlag GmbH \& Co. KGaA, Weinheim, ISBN: 3-527-31320-6, 645 p.

36. Maxwell, J.C. L. On the calculation of the equilibrium and stiffness of frames. The London, Edinburgh, and Dublin Philosophical Magazine and Journal of Science, 1864, Vol. 27, 182, p. 294-299. doi:10.1080/14786446408643668.

37. Calladine, C.R. Theory of Shell Structures, Cambridge University Press, Cambridge, UK, 1983.

38. Pellegrino, S., Calladine, C.R. Matrix analysis of statically and kinematically indeterminate frameworks, International Journal of Solids and Structures, Vol. 22, 4, 1986. P. 409-428. Doi:10.1016/0020-7683(86)90014-4.

39. Deshpande, V.S., Ashby, M.F., Fleck, N.A. Foam topology: bending versus stretching dominated architectures, Acta Materialia, Vol. 49, 6, 2001, P. 1035-1040. Doi:10.1016/S1359-6454(00)00379-7.

40. Deshpande, V.S., Fleck, N.A., Ashby, M.F. Effective properties of the octet-truss lattice material, Journal of the Mechanics and Physics of Solids, Vol. 49, 8, 2001, P. 1747-1769, doi:10.1016/S0022-5096(01)00010-2.

41. Guest, S.D. Tensegrities and rotating rings of tetrahedra: a symmetry viewpoint of structural mechanics, Philos. Trans. R. Soc. Lond. A, 2000, Vol. 358, p. 229-243. DOI: 10.1098/rsta.2000.0529.

42. Yablonovitch E., Gmitter T.J. Photonic band structure: The face-centered-cubic case, Phys. Rev. Lett. Vol. 63, 18, (1989) p. 1950 . 
43. Yablonovitch E. Photonic band-gap structures, Journal of the Optical Society of America B, Vol. 10, 2, pp. 283-295, (1993), doi: 10.1364/JOSAB.10.000283.

44. Sajeev J., Strong localization of photons in certain disordered dielectric superlattices, Phys. Rev. Lett. 58, 2486 (1987).

45. Colvin V.L. From Opals to Optics: Colloidal Photonic Crystals, MRS Bulletin, Vol. 26, No 8, 2001, pp. 637 - 641, DOI: http://dx.doi.org/10.1557/mrs2001.159.

46. Biswas R., Sigalas M.M., Subramania G., Ho K.-M., Photonic band gaps in colloidal systems, Phys. Rev. B, Vol. 57, 7 (1998), p. 3701.

47. Busch K., Sajeev J., Photonic band gap formation in certain self-organizing systems, Phys. Rev. E, Vol. 58,3 (1998) p. 3896.

48. Jiang P., Hwang K.S., Mittleman D.M., Bertone J.F., and Colvin V.L., Template-Directed Preparation of Macroporous Polymers with Oriented and Crystalline Arrays of Voids, Journal of the American Chemical Society 1999 121 (50), $11630-11637$. DOI: $10.1021 /$ ja9903476.

49. Park S.H., Xia Y., Fabrication of Three-Dimensional Macroporous Membranes with Assemblies of Microspheres as Templates, Chem. Mater., 1998, 10 (7), pp. 1745-1747. DOI: 10.1021/cm9801993.

50. Deutsch, M., Vlasov, Yu.A. and Norris, D.J. (2000), Conjugated-Polymer Photonic Crystals. Adv. Mater., 12: 1176-1180. doi:10.1002/1521-4095(200008)12:16<1176::AID-ADMA1176>3.0.CO;2-H.

51. Blanco A., Chomski E., Grabtchak S., Ibisatge M., John S., Leonard S.W., Lopez C., Mesegeur F., Miguez H., Mondia J.P., Ozin G.A., Toader O., and van Driel H.M., Large-scale synthesis of a silicon photonic crystal with a complete three-dimensional bandgap near 1.5 micrometres, Nature, Vol. 405 №6785, (2000) p. 437. doi:10.1038/35013024.

52. Deniskina N. D., Kalinin D. V., Kazantseva L.K. Noble opals, their synthesis and genesis in nature. Novosibirsk: Science, 1980. 64 p. (In Russian).

\section{INFORMATION ABOUT THE AUTHOR}

Pavel G. Kudryavtsev, Professor, PhD in Chemistry, Deputy Director for Research and Development Polymate Ltd - Israel Nanotechnology Research Center (Israel), Academician of International Academy of Sciences for Ecology and Human Safety and Russian Academy of Natural Sciences, Author of 254 scientific works, including 4 monographs, has 35 inventions. He was awarded the M.V. Lomonosov medal, Commander of the Order «The Star of the Scientist» and was awarded the honorary title «Honored Worker of Science», awarded the medal of P.A. Stolypin, and honorable diamond sign of the Chamber of Commerce and Industry of the Russian Federation. Polymate Ltd - Israel Nanotechnology Research Center, POBox 73, Migdal HaEmek 2310001, Israel, e-mail: pgkudr89@gmail.com 